\title{
Test of a Model of Psychosocial Resources, Stress, and Health Among Undereducated Adults
}

\author{
Janet S. Barnfather, ${ }^{1 *}$ David L. Ronis ${ }^{2 \dagger}$ \\ ${ }^{1}$ The University of Michigan-Flint, Department of Nursing, 552 CROB, Flint, MI 48502-2186 \\ ${ }^{2}$ Department of Veterans Affairs and The University of Michigan-Ann Arbor, Ann Arbor, MI \\ Received 27 January 1998; accepted 5 September 1999
}

\begin{abstract}
The purpose of this study was to test a model drawn from the Modeling and RoleModeling theory depicting relationships among psychosocial resources, perceived stress, and health for undereducated adults. A purposive sample of 171 adults enrolled at an urban adult education center completed several self-report measures: Modified Erikson Psychological Stage Inventory, Basic Need Satisfaction Inventory, Perceived Stress, and Positive Health Index. Based on a structural equation modeling analysis, psychosocial development and basic need satisfaction had significant direct effects on health, with the expected positive signs. Psychosocial development had the strongest direct effect on health and also had a strong direct effect on basic need satisfaction and an indirect effect on health. Support for the hypothesized model has important implications for nursing and other community-based care provider interventions regarding health, including strengthening psychosocial resources. ๑ 2000 John Wiley \& Sons, Inc. Res Nurs Health 23:55-66, 2000
\end{abstract}

Keywords: model testing; psychosocial resources; health; undereducated adults

Educational attainment, as a key component of socioeconomic status, is a strong predictor of health and well-being (Garrison, Gold, Wilson, \& Kannel, 1993; MacKenzie et al., 1998; Pappas, Queen, Hadden, \& Fisher, 1993; Williams, 1990). Associations between education and health remain highly significant after controlling for income and occupation, two other indicators of socioeconomic status (Winkleby, Fortmann, \& Barrett, 1990). Furthermore, among older African Americans and Whites, the level of education has a greater effect than race on health (Guralnik, Land, Blazer, Fillenbaum, \& Branch, 1993). Individuals with less than a high school education are especially vulnerable to poor health and do not experience the postponement or "compression" of morbidity and functional disability that occurs in the subgroups with higher educational levels (Danziger \& Gottschalk, 1995; House et al., 1990; Kessler, Foster, Saunders, \& Stang, 1995; National Center for Health Statistics, 1993).

It is important to understand why this relationship occurs. Such understanding can guide development of intervention programs (Grossman \& Joyce, 1989; Igoe \& Giordano, 1992). Psychosocial factors that underlie the vulnerability of those with less education remain incompletely understood, and the psychosocial processes that affect health and well-being in adults with low educational attainment have not received adequate attention from health care providers interested in health promotion programs (Adler, Boyce, Chesney, Folkman, \& Syme, 1993; Blane, 1995; Syme, 1987).

The assistance of Mary Ann Swain, Ph.D., and Lois Rosen, Ph.D., for manuscript editing and Yvonne Eaves in data collection for this study was greatly appreciated.

Contract grant sponsors: The Office of Vice President for Research, The University of Michigan, Ann Arbor; Sigma Theta Tau International, Rho Chapter, Ann Arbor, MI.

Correspondence to Janet S. Barnfather.

*Associate Professor.

†Research Health Science Specialist. 
The purpose of this study was to examine predictors of health for undereducated adults, individuals without a 12th-grade education enrolled in an adult education program, using major constructs from the Modeling and Role-Modeling (MRM) theory (Erickson, Tomlin, \& Swain, 1988). MRM theory is especially useful in this population because it has a clear focus on human development, needs, and health. MRM is a nursing theory that synthesizes concepts from several theories, including those of psychosocial development, human needs psychology, and stressadaptation to examine the health of individuals across the life span in a range of clinical practice settings. Human needs psychology refers to basic need satisfaction (physical, safety/security, belonging/love, esteem/self-esteem) and growth needs (self-actualization) (Goble, 1974; Maslow, 1968, 1970). Psychosocial development is defined as a process by which individuals acquire attributes associated with trust, autonomy, initiative, industry, identity, intimacy, generativity, and integrity, which contribute to growth and health (Erikson, 1982; Erickson et al., 1988). Erickson and colleagues (1988) have suggested that basic need satisfaction and psychosocial development contribute to psychosocial resources on which individuals rely. According to MRM theory, the availability of psychosocial resources influences one's ability to resolve a situation adaptively, with minimal stressful effects. Psychosocial resources may be internal or external. Internal and external resources are developed over time as basic needs are satisfied and developmental tasks are accomplished successfully.

MRM theory posits that psychosocial resources influence the ability to contend with stress. Stressadaptation is captured within the concept of adaptive potential that has biophysical and psychological components, and is conceptually defined as the ability to mobilize coping resources to contend with stressors (Barnfather, Swain, \& Erickson, 1989a; Erickson, 1976; Erickson \& Swain, 1982). Stressors are stimuli that precede and elicit stress. Stress is a nonspecific response of the person to any demand. Coping is the process of contending with external and internal stressors and can be adaptive (growth and health directed) or maladaptive (illness directed). Adaptive potential is the broadest concept and contains a psychological component identified as perceived stress. MRM theory synthesizes several theories into a nursing perspective to better understand the client's view of the world (model). Role-modeling means helping individuals redesign their model of the world by assisting them in developing a healthier role(s) and includes planning and purposeful intervention. Health is defined as a state of physical, mental, and social well-being, not merely the absence of disease or infirmity (World Health Organization, 1988). Health connotes a state of dynamic equilibrium among various human subsystems (Erickson et al., 1988).

Figure 1 contains the theoretical model relating several of the main constructs in the MRM theory and demonstrates the hypotheses of the study. If psychosocial resources are weak, then a resource deficit exists that directly affects health. The ability to contend with stress is directly related to the availability of these psychosocial resources and resources are directly related to health (Kinney \& Erickson, 1990). The three constructs (a) psychosocial development, (b) basic need satisfaction, and (c) perceived stress are considered major contributors to health. The more positive the achievement of psychosocial development, the more likely that basic needs are satisfied, and positive psychosocial development and basic need satisfaction means it is less likely that one will be overwhelmed by stress. Psychosocial development facilitates human growth and psychosocial maturity promotes health and well-being. Within the MRM theoretical perspective, psychosocial development and basic needs satisfaction are sources of psychosocial resources for individuals to draw upon. These resources enable them to avoid or minimize the harmful and discomforting effects of stress (Erickson et al., 1988; Kline Leidy, Ozbolt, \& Swain, 1990).

Erickson et al. (1988) proposed that the relationships among the major constructs in MRM are relevant across the life span for the purpose of understanding both ill and healthy populations. Given the current state of model testing, MRM theory has been shown to be a promising systematic approach for nurses to use in generating a body of knowledge on which to base professional practice (Acton, Irvin, \& Hopkins, 1991). Kinney and Erickson (1990) reviewed the importance of interrelationships among psychosocial development, basic needs, and perceived stress in hospitalized individuals and individuals in the community. Psychosocial development was found to be positively related to health outcomes for both healthy and ill persons. In one study, measures of psychosocial development derived from trust, autonomy, and initiative, and measures of satisfaction with daily living were examined using multiple regression to predict health status (Erickson, 1984). Aspects of psychosocial development predicted satisfaction with daily life, and as satisfaction with life decreased, there was an increased perception 


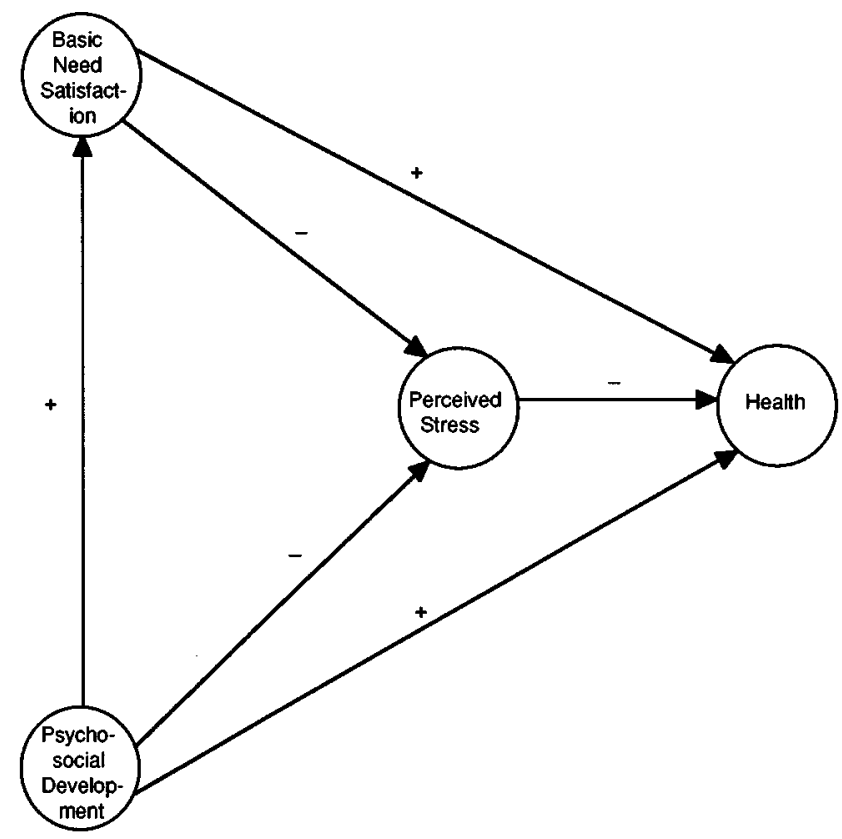

FIGURE 1. Major constructs in the Modeling and Role-Modeling theory.

of poor health, and an increased number of health problems emerged.

Results of several studies (Barnfather et al., 1989a; Erickson, 1976; Erickson \& Swain, 1982) have supported the construct validity of adaptive potential when operationalized using biophysical and psychological measures (perceived stress). In a study of hospitalized patients, researchers found that individuals who had the worst adaptive potential had the longest length of hospital stay (Erickson \& Swain). In a study of college students, Barnfather et al. (1989a; 1989b) found that low adaptive potential was associated with thoughts of dropping out of school. Another study with undereducated adults enrolled in an adult education program indicated adaptive potential was useful in predicting attendance rates (Barnfather, 1988). Multidimensional scaling analysis supported the hypothesis that basic need satisfaction and adaptive potential are directly related (Barnfather, 1993).

The importance of basic need satisfaction in personal resource availability is central to MRM (Erickson et al., 1988). Acton (1993) used a theoretically derived causal model approach to study the well-being of caregivers for individuals who have dementia. Several propositional statements were examined regarding basic need status, stressadaptation, and well-being; basic need satisfaction was a strong predictor of well-being. The total model accounted for $49 \%$ of the variance in wellbeing. Leidy (1990) proposed and tested a theorybased structural model describing the relationships among the major MRM constructs of psychosocial development, basic need satisfaction, and perceived stress for people with chronic obstructive pulmonary disease (COPD). Psychosocial development was determined to be a useful predictor of basic need satisfaction; basic need satisfaction was a predictor of perceived stress. In general, psychosocial development was a significant predictor of basic need satisfaction for both sexes. The model explained 39\% of the variance in symptomatic experience of COPD. Both studies support the theoretical proposition linking basic need satisfaction to health and wellbeing, but only Leidy (1990) addressed the importance of both psychosocial development and basic need satisfaction contributing to psychosocial resources.

The MRM theory has been useful in multiple studies to understand more about health and wellbeing in ill and healthy populations. There is support for validity of the model proposed in Figure 1 ; however, most of the research has examined bivariate relationships or has required meeting various implausible assumptions. For example, regression analysis assumes that predictor variables are measured without error and is biased by random measurement error in the predictors (Bollen, 
1989). None of the studies have used structural equation modeling with latent variables that have multiple indicators. Structural equation modeling does not make the unrealistic assumption of no measurement error in the predictors and is not biased by random measurement error (Bollen). The purpose of this study was to test the MRM hypothesized, theoretical relationships proposed in Figure 1 among undereducated adults using structural equation modeling with latent variables.

The theoretical propositions in this study have potential to assist community-based health care professionals, including advanced practice nurses and school nurses, in their interdisciplinary approach to health promotion with undereducated adults and their families. Nurses have recognized the importance of psychosocial processes when working with undereducated adults, and have shown that nurse interventions can be theoretically based; there is, however, little research to guide these interventions (Barnfather, 1991). Nurses encounter undereducated adults in multiple settings, including hospitals and clinics, as well as adult education centers and when these adults are the parents of school-aged children, where family involvement is the most effective focus of care (Uphold \& Graham, 1993).

\section{METHOD}

\section{Sample}

A purposive sample of 186 undereducated students enrolled at an urban adult career education center completed self-report questionnaires over a 1 -hr session in classroom settings. The director of the center used simple random sampling to select the classrooms included in the study, and the teachers selected the day and time. According to Bentler \& Chou (1987), the sample size is adequate for structural equation analysis because there are at least five cases per free parameter.

Ages of the students ranged from 17 to 47 years $(M=27.9, S D=7.7)$. The majority were female $(81 \%, n=151)$ and single $(64 \%, n=120)$. Most indicated they were not high school graduates $(95 \%, n=176)$. The remaining 10 students in the sample were high school graduates with less than a semester of postsecondary education. The reported educational levels of class attendance were below 9 th grade $(12 \%, n=23)$, 9 th grade $(20 \%, n$ $=37), 10$ th grade $(16 \%, n=30), 11$ th grade $(25 \%$, $n=47)$, currently attending 12 th grade $(21 \%, n=$ 39). A large majority reported their personal incomes as below $\$ 10,000$ per year $(89 \%, n=166)$ and household income below $\$ 15,000(87 \%, n=$ 162). Students identified their ethnicity as African American (68\%, $n=126)$, Caucasian $(25 \%, n=$ $47)$, Hispanic $(3 \%, n=5)$, other $(3 \%, n=6)$, and unspecified $(1 \%, n=2)$. The sample represented approximately $21 \%$ of the total 580 students enrolled for the semester in the adult education center at which data were collected. Nonparticipants were students not taking the selected classes and those who were absent from the selected classes on data collection days. Although participation was voluntary, no student refused to participate.

\section{Measures}

Psychosocial development. Psychosocial development was assessed with the Modified Erikson Psychological Stage Inventory (MEPSI), which was designed to measure psychosocial maturation related to Erikson's eight stages of psychosocial development (Darling-Fisher \& Kline Leidy, 1988). The MEPSI measures specific psychosocial attributes that arise from progression through each of the eight stages. The MEPSI is a self-report instrument that contains 80 items rated on a 1- to 5-point scale, hardly ever true to almost always true. Higher scores (4-5) indicate a predominance of positive attributes reflecting successful psychosocial maturation, that is, the higher the score the stronger the positive attributes. Lower scores (1-2) indicate a predominance of negative attributes, reflecting less successful psychosocial maturation. An overall mean score was computed that reflects the degree of psychosocial attribute strength across stages. The overall mean score can be used to detect developmentally related strengths and limitations (Leidy, 1990). Example items include: other people understand me; I really believe in myself; and I like to assume responsibility for things. Findings from secondary analyses of four studies indicate that the MEPSI is relatively stable across diverse populations; alpha coefficients for the total MEPSI range from .93 to .97 (Leidy \& Darling-Fisher, 1995). In addition,

Table 1. Mean Scores for All Scales $(n=171)$

\begin{tabular}{lccc}
\hline Scale & $\boldsymbol{M}$ & $\boldsymbol{S} \boldsymbol{D}$ & Range \\
\hline MEPSI & 3.65 & .46 & $1.9-4.5$ \\
BNSI & 5.09 & .53 & $3.5-5.9$ \\
Perceived Stress & 3.30 & .81 & $1.3-5.0$ \\
PHI & 4.13 & .56 & $2.9-6.0$ \\
\hline
\end{tabular}

Note. MEPSI = Modified Erikson Psychological Stage Inventory; BNSI = Basic Need Satisfaction Inventory; PHI = Positive Health Index. 
construct validity was evident in the relationships found between chronological age and total score $(r=.19, p<.05, n=163)$. The total scale had an alpha coefficient of .92 in this study.

Although the MEPSI includes eight subscales corresponding to Erikson's eight stages (1982), the high correlations among subscales and the high internal consistency of the overall scale justify the current researchers' and past researchers' (Darling-Fisher \& Kline Leidy, 1988; Leidy \& Darling-Fisher, 1995) use of the MEPSI as a single scale and our modeling of it as a unidimensional measure of psychosocial development. The mean scores for the MEPSI and all other scales are displayed in Table 1.

Basic need satisfaction. Basic need satisfaction was assessed using the Basic Need Satisfaction Inventory (BNSI), which was developed (Kline, 1988) by selecting and refining items from a large national survey conducted on the Quality of Life scale (Andrews \& Withey, 1974). The theoretical framework for selection of items was drawn from the work of Maslow (1970) on fulfillment of physical, safety, belonging, self-esteem, and self-actualization needs. The BNSI contains 27 self-report items to rate on a scale from 1-7, with higher scores indicating greater basic need satisfaction. An overall basic need satisfaction score is obtained by calculating a mean for all items. Example items include: my physical needs are met; I am secure from people who might steal or destroy my property; and I have the chance to know people with whom I can really feel comfortable. The scale was scored as the mean rating on the 27 items, indicating an overall sense of need satisfaction. The total scale had an alpha of .89 in this study. Validity and reliability testing of the scale has been reported (Leidy, 1994), and alpha reliability levels of the total scale in both ill and healthy individuals range from .89 to .93 . Construct validity was supported by testing relationships between the BNSI and Self Transcendence (ST), defined as the capacity to extend the self beyond personal concerns and take a broader life perspective (Reed, 1991). In a sample of healthy adults, a measure of ST correlated significantly with the BNSI total scale $(n=.58, p<.001, n=$ 58).

Perceived stress. Perceived stress was measured by asking subjects to rate two items: (a) I have a lot of stress in my life, and (b) How often are you stressed more than you want to be. The questions were rated on a 5-point scale: 1 (almost never) to 5 (almost always). Higher scores on the scale indicate more perceived stress. The alpha coefficient was .79 in this study, which is particular- ly high for a two-item scale (Nunnally, 1978). After consulting with MRM experts, the two-item scale was judged by the first author to capture psychological components of perceived stress that were consistent with MRM theory (Erickson et al., 1988).

Health. Health was considered a state of increased effectiveness in dealing with the self and environment and as a positive phenomenon, rather than as the absence of disease. The person is viewed as a multidimensional, holistic being: physical, psychological, social, and spiritual. Health was represented in two ways: (a) The Positive Health Index (PHI), which required respondents to rate their health on a 6-point scale of 1 (always untrue) to 6 (always true), and (b) a single self-report item about overall health on a 6-point scale from 1 (sickest) to 6 (healthiest). The PHI has 47 items to rate, with a higher score indicating better health. The PHI was developed after a careful literature review that resulted in identifying the concept of positive health (Miller, 1989). Content validity was reported by Miller, who developed positive health dimensions by reviewing and synthesizing the literature (Antonovsky, 1979; Belloc, Breslow, \& Hochstim, 1971; Dunn, 1961; Pender \& Pender, 1987). Example items are (a) I go over and over my problems more than I should (reverse scored), (b) I give $100 \%$ to the things I do, (c) I listen carefully to what people say, (d) I have a hard time doing what is good for my health (reverse scored), and (e) I eat well balanced meals. The PHI score, indicating overall positive health, yielded an alpha reliability estimate of .97 for the aggregate measure (Miller). Alpha reliability level in this study for the aggregate measure was .83 .

\section{Procedure}

Before approaching potential subjects, the first author consulted with the director and attended meetings at the center to discuss the study with the teachers and staff. During these meetings the study was explained and questions answered. Several experienced teachers reviewed the study questionnaires and rated them at 4th grade through 6th grade levels, appropriate levels for their students, according to the Fry Readability Graph (Fry, 1968). In addition, the investigator conducted a pilot study $(N=10)$ for readability with students who were attending the center but who were not included in the study. These students had comments about the reading level difficulty that reflected their need for reassurance about the meaning of some items. After the investigator confirmed their understanding, students were able to 
verbalize accurately the intent of the items in their own words. Teachers announced in their classes that a study would be conducted at the center in which students would complete several questionnaires over a 1-hr period in their classrooms and for which they would immediately receive $\$ 5.00$ in cash. A female, African American doctoral student familiar with the principal investigators' project and the center administered the study questionnaires and paid participants (Porter \& Villarruel, 1993).

\section{Indicators Used In Data Analysis}

Following the approaches of Marsh, Antill, and Cunningham (1989) and Stacy, Bentler, and Flay (1994), we randomly assigned each item of the MEPSI to one of three subscales, calculated the three subscale scores as means, and modeled psychosocial development as a unidimensional latent variable with the three subscales as indicators. The same approach was followed to create three indicators from the original items in the BNSI and the PHI. Thus, three indicators were developed for three of the latent variables, psychosocial development, basic need satisfaction, and health, by using items from the appropriate instrument and randomly splitting the respective items into three new indicators for each latent variable. An additional self-report item served as a fourth indicator of health.

This approach creates new indicators called parcels. The latest research on parceling indicates that when certain conditions, including unidimensionality of each scale, are met, analysis using three parcels per factor will produce the same estimates of the relationships between factors as structural equation modeling using the individual items (Marsh, Hau, Balla, \& Grayson, 1998). Important advantages to analyzing responses for parcel scores are (a) scores typically have greater reliability and generality, (b) response biases and other characteristics that are idiosyncratic to individual items are likely to have less influence, (c) the distribution of scores is more nearly normal, and (d) the model has many fewer parameters to estimate (Marsh et al., 1989; Stacy et al., 1994). Parceling was not needed for the two stress items that were used as indicators for the latent variable perceived stress. Using two indicators to measure a latent variable is supported in structural equation modeling literature (Byrne, 1994; Hayduk, 1987).

Without the parceling approach, structural equation modeling using the individual item data would have involved analysis of a 157-by-157 covariance matrix with a structural equation model including over 300 free parameters, which is not practical. Parceling was used to bring the analytic task down to manageable size: analysis of a 12-by12 covariance matrix using a structural equation model with 29 free parameters. Careful consideration led to the parceling approach, despite the fact that information specific to individual items of the original instrument will be unknown.

Parceling in this study is consistent with MRM theory, which is founded on the belief that individuals have a continuous potential for growth, development, and health throughout their life span (Erickson et al., 1988; Fitzpatrick \& Whall, 1989). Parceling is also consistent with the findings that the originally proposed subscales of the MEPSI correlate highly with each other as expected for a unidimensional scale. A general goal of the MRM theory is to focus on satisfaction of basic needs, promotion of psychosocial development, and adaptation to contend with stress to explain differences in health.

\section{RESULTS}

Structural equation modeling was conducted employing the EQS program using maximum likelihood estimation on the covariance matrix from subjects $(n=171)$ with complete data (Byrne, 1994). These subjects represent $92 \%$ of persons in the study. Subjects excluded from the analysis due to missing data were similar to those included with regard to health and demographic characteristics.

A confirmatory factor analysis model was estimated with the proposed indicators to assess the measurement of the constructs and the strengths of the associations among them. None of the indicators were allowed to load on more than one factor, and each indicator was found to load significantly on its construct $(p<.01)$. One indicator (the single item self-rating of health) had only a weak loading (.2) on its factor. All other measures had strong loadings, over .75. Modification indices did not suggest any meaningful changes that would improve the fit.

The chi-square test indicated that the hypothesized factor analysis model could be statistically rejected, $\chi 2(48, n=171)=72.3, p=.01$, indicating that the confirmatory factor analysis model did not perfectly fit the data. Rejection of models as an exact fit to the data is typical of structural equation modeling except when sample sizes are very small. Because of this, various practical measures of fit have been developed, such as the NonNormed Fit Index (NNFI; Bentler \& Bonett, 1980) and the Comparative Fit Index (CFI; Bentler,
AUQ:

MSP049 
1990). The NNFI and CFI can both be viewed as estimates of the proportion of information in the covariance matrix that is explained by the model. They range from 0 to 1 with values over .95 indicating good fit (Hu \& Bentler, 1999). Both the NNFI and the CFI for the confirmatory factor analysis model were .98 .

In addition to assessing fit and the loadings of the indicators on the factors, confirmatory factor analysis also produces estimates of the disattenuated correlations among the factors. These are estimates of how strongly the factors would correlate with each other if each factor was measured without error. According to estimated disattenuated correlations, health was most strongly associated with psychosocial development (.71), whereas basic need satisfaction (.52) and perceived stress $(-.49)$ also were associated strongly with health. These constructs were all hypothesized to directly affect health, and each correlation was significant $(p<.05)$ and had the hypothesized sign (Figure 1). These constructs were significantly correlated with each other: basic need satisfaction with psychosocial development (.55), psychosocial development with perceived stress $(-.51)$, and basic need satisfaction with perceived stress $(-.42)$.
Having established a good fitting measurement model in the confirmatory factor analysis, we then estimated the path model, with results shown in Figure 2. The chi-square test indicated that the path model could be rejected as a perfect fit to the data, $\chi 2(48, n=171)=72.3, p=.01$. Again the NNFI and CFI were .98 , indicating a good fit. All the paths in the model were statistically significant at $p<.05$, except the path from perceived stress to health, which did not reach significance $(p=.09)$. The coefficients of all paths in Figure 2 had the predicted signs. The model explained 55\% of the variance in health. Examination of the estimated path model and further analyses revealed that psychosocial development had the strongest direct and indirect paths to health, whereas stress had the weakest (and nonsignificant) path to health.

Table 2 shows the decomposition of the relationships in the model based on the data and on the assumptions of (a) causal closure (no two factors in the model are both influenced by a factor not in the model) and (b) weak causal ordering (causal influences do not run in directions opposite to those specified by the model) (Williams \& DeLurgio, 1994). The most notable findings are that the

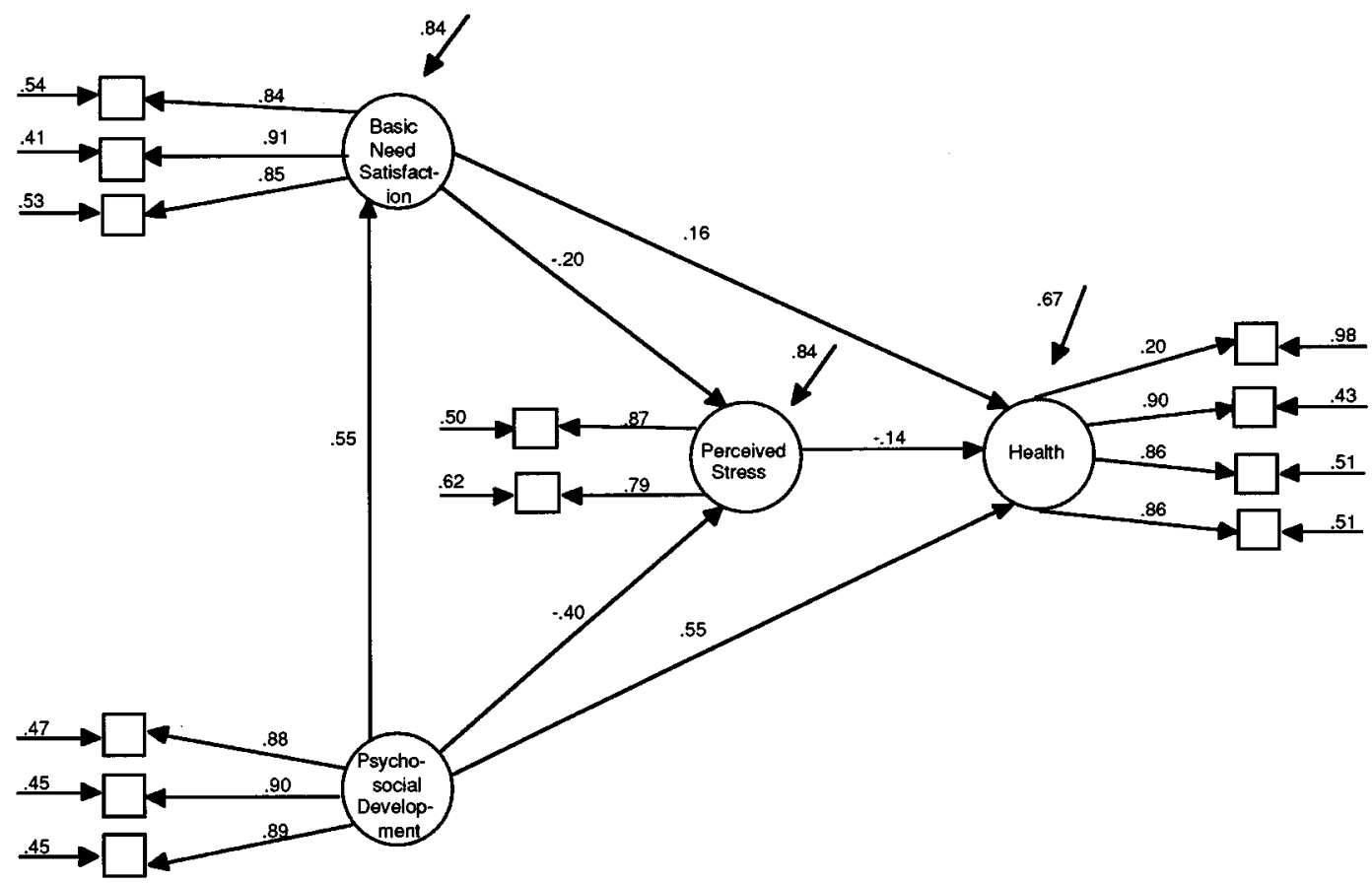

FIGURE 2. Estimated model of psychosocial development, basic need satisfaction, perceived stress, and health. All coefficients are standardized. All paths are statistically significant $(p<.05)$ except the path from Perceived Stress to Health. 
Table 2. Decomposition of Bivariate Relationships Among the Constructs

\begin{tabular}{lcrrrr}
\hline & & \multicolumn{2}{c}{ Causal Effects } & & Noncausal \\
\cline { 2 - 6 } Relationship & $\begin{array}{c}\text { Disattenuated } \\
\text { Correlation }\end{array}$ & Direct & Indirect & Total & Effect \\
\hline Stress with health & -.49 & -.14 & .00 & -.14 & -.35 \\
Basic needs with health & .52 & .16 & .03 & .19 & .33 \\
Psychosocial development with health & .71 & .55 & .16 & .71 & .00 \\
Basic needs with stress & -.42 & -.20 & .00 & -.20 & -.22 \\
Psychosocial development with stress & -.51 & -.40 & -.11 & -.51 & .00 \\
Psychosocial development with basic needs & .55 & .55 & .00 & .55 & .00 \\
\hline
\end{tabular}

strong correlations of stress and basic needs with health are mostly noncausal in nature. Assuming that the form of the model is correct, the main reason for the correlations of basic need and stress with health is that all three of the factors are strongly influenced by psychosocial development. In contrast to these findings are the results of the decomposition of the correlation between psychosocial development and health. The form of the theoretical model implies that this strong relation$\operatorname{ship}(r=.71)$ is entirely causal. The estimation of the model and the decomposition of the relationship indicate how much of the effect is direct and how much is indirect, mediated by basic need satisfaction and stress. Results show that most of the relationship is due to the direct causal path (.55) with only a minimal influence (.16) through the two mediating variables.

\section{DISCUSSION}

The theoretical model was an excellent fit to the data and accounted for more than half of the variance in health, which supports the rationale for use of MRM theory to predict health for undereducated adults. Undereducated individuals are at risk for poor health. MRM theory can provide a valid basis to understand more about why educational attainment is related to health.

The proposed model in this study is consistent with the theoretical linkages contained in the MRM theory (Erickson et al., 1988). In the study model, psychosocial development and basic need satisfaction had significant direct effects on health, with the expected positive signs. Psychosocial development had the strongest direct effect on health and also had a strong direct effect on basic need satisfaction and an indirect effect on health (Table 2 ). MRM theory suggests that psychosocial development and basic need satisfaction are central to growth and health. The model is consistent with an approach that supports psychosocial development as an important base that directly influences health. The findings from this study (especially the .55 path from psychosocial development to basic need satisfaction) are consistent with previous research results that psychosocial development is a good predictor of how well basic needs are met (Leidy, 1990).

Taken together, the two constructs, psychosocial development and basic need satisfaction, are identified as the sources of psychosocial resources from which individuals can draw to contend with stress (Leidy, 1990). Since positively resolved psychosocial development as well as basic need satisfaction were related to lower perceived stress (with path coefficients of -.40 and -.20 ), the results support the proposed view that psychosocial development and basic need satisfaction are important psychosocial resources for undereducated individuals as they contend with stress. Interestingly, there have been recent literature reports that psychosocial resources were important predictors of morbidity and mortality, and less formal education contributed to worse health outcomes (Bernstein \& Carmel, 1996).

Early and on-going attention to psychosocial development can directly and indirectly influence health for adults (Walsh, 1996). Nationally, insufficient human development limiting health as well as ability to address critical basic needs of nutrition, housing, and safety are at unacceptably high levels (Lavin, Shapiro, \& Weill, 1992). Neglected developmental and basic needs of individuals in our society will be precursors to adult lives of dependency and poor health. Programs at schools must include collaborative professional services for biophysiological, psychosocial, and cultural components to solve interrelated education, social, economic, and health care problems (Uphold \& Graham, 1993). Findings from the current study support careful attention to these components as 
predictors of health. In addition, health, as a positive phenomenon, is consistent with new paradigms for community health, which include a restructured approach to health care toward health promotion and disease prevention (Igoe \& Giordano, 1992; Pender, Barkauskas, Hayman, Rice, \& Anderson, 1992).

In this study and in the Irvin and Acton study (1996) in which a general health questionnaire was administered to measure health, there was no significant relationship between perceived stress and health. One possible explanation for the finding may be related to the conceptualization and measurement of health as a positive concept. An intensive review and synthesis of the literature suggests that stress-health linkages have been measured using categories such as affective status, symptoms related to an illness or condition, and complications (Barnfather \& Lyon, 1992). In this study, health was operationalized in a way that was consistent with the theoretical definition of health as physical, mental, and social well-being and not merely the absence of disease (WHO, 1988). In addition, the two-item measurement of perceived stress may have not captured the full range of possibilities for individuals in the study. Finally, the theoretical linkage between perceived stress and health may be questionable, given the recent synthesis of the empirical literature (Werner \& Frost, in press).

A limitation of the current study is the crosssectional sample. With such a design, it is impossible to establish the direction of causal relationships among constructs. No statistical analysis, including structural equation modeling, can insure causality. The directions of causality in the model are theoretically based rather than experimentally demonstrated. The authors suggest that future researchers use either longitudinal data or experimental manipulations or both to establish these paths more firmly. In addition, a purposive sample and moderate sample size are methodological limitations to consider improving upon in future studies.

Recommendations for further research include rigorous intervention studies to specifically address MRM theoretical propositions in clinical practice with undereducated adults. Such studies would include developing and testing interventions to facilitate psychosocial developmental growth and basic need satisfaction. Concurrent measurement of health for these adults should be examined. Programs for advancing educational attainment are a highly important consideration for a healthy nation (Lavin et al., 1992). Intervention studies can be based on guidelines in the agenda for change through community-based research (Lavin et al.), which will be central to creating a healthy future for undereducated individuals. A national research agenda that is consistent with the previously mentioned approaches includes (a) psychological and sociological status of youth cohorts; (b) responses to life transitions such as divorce, changing residences, and death of significant family members; (c) circumstances such as acute illness, chronic health conditions, domestic violence, tobacco/drug/alcohol use, and (d) behaviors that are health-enhancing or health-threatening (Bradley, 1998). The national research agenda has an important community-based focus to improve health outcomes.

Advanced practice nurses (APNs) influence health outcomes in community-based settings. APNs in school-based centers plan to include systematic psychosocial assessment as they study alternative models of care in which quality is defined in terms of health, prevention, cost-effectiveness, and patient satisfaction (Walker, Baker, $\&$ Chiverton, 1998). There are trends for APNs to function as primary care providers in school-based health centers and to move toward delivery of health care in a variety of settings including rural and urban neighborhoods. Primary care services include basic laboratory services and the prescription of medications; however, psychosocial resource assessment is also an important aspect of the care provided by ANPs as a basis for their direct care and for providing appropriate referrals and follow-up. Nurses in community-based settings are particularly concerned with the effectiveness of their interventions related to psychosocial resource assessment for low-income and undereducated women (Reutter, Neufeld, \& Harrison, 1998).

Nurses who use the concepts and relationships contained in this model could sharpen their observations and facilitate their understanding of human responses to inform interventions (Campbell, Finch, Allport, Erickson, \& Swain, 1985; Kinney \& Erickson, 1990; Rogers, 1996; Sappington \& Kelly, 1996). Clinical nursing interventions might include strengthening psychosocial resources and focusing on the client's perceived needs through a highly interactive process involving decisionmaking and problem-solving skills. The approach focuses on tailoring interventions to specific psychosocial needs of individuals, which appears to be strongly related to cost-effective health care (Sobel, 1995). The findings demonstrate support to proceed cautiously with this approach and continue to bridge the practice-research-theory gap (Erickson et al., 1988; Acton et al., 1991). 


\section{REFERENCES}

Acton, G.J. (1993). The relationships among stressors, stress, affiliated-individuation, burden, and wellbeing in caregivers of adults with dementia: $\mathrm{A}$ test of the theory and paradigm for nursing, Modeling and Role-Modeling. Unpublished doctoral dissertation, University of Texas at Austin.

Acton, G.J., Irvin, B.L., \& Hopkins, B.A. (1991). Theory testing research: Building the science. ANS: Advances in Nursing Science, 14(1), 52-61.

Adler, N.E., Boyce, W.T., Chesney, M.A., Folkman, S., \& Syme, S.L. (1993). Socioeconomic inequities in health. Journal of the American Medical Association, 269, 3140-3145.

Andrews, F., \& Withey, S. (1974). Developing measures of perceived life quality: Results from several national surveys. Social Indicators Research, 1, 126.

Antonovsky, A. (1979). Health, stress and coping. San Francisco: Jossey-Bass.

Barnfather, J.S. (1988). Instrumentation issues for determining adaptive potential status. Unpublished manuscript, The University of Michigan, Ann Arbor.

Barnfather, J.S. (1991). Restructuring the role of school nurse in health promotion. Public Health Nursing, 8, 234-238.

Barnfather, J.S. (1993). Testing a theoretical proposition for modeling and role-modeling: Basic need and adaptive potential status. Issues in Mental Health Nursing, 14, 1-18.

Barnfather, J.S., \& Lyon, B.L. (Eds.). (1992). Stress and coping: State of the science and implications for nursing theory, research and practice. Monographs of Sigma Theta Tau International (Series 93). Indianapolis, IN: Sigma Theta Tau International.

Barnfather, J.S., Swain, M.A.P., \& Erickson, H.C. (1989a). Construct validity of an aspect of the coping process: Potential adaptation to stress. Issues in Mental Health Nursing, 10, 23-40.

Barnfather, J.S., Swain, M.A.P., \& Erickson, H.C. (1989b). Evaluation of two assessment techniques for adaptation to stress. Nursing Science Quarterly, 2, 172-182.

Belloc, N., Breslow, L., \& Hochstim, J.R. (1971). Measurement of physical health in a general population survey. American Journal of Epidemiology, 93, 328 336.

Bentler, P.M. (1990). Comparative fit indexes in structural models. Psychological Bulletin, 107, 238-246.

Bentler, P., \& Bonett, D. (1980). Significance tests and goodness-of-fit indices in the analysis of covariance structures. Psychological Bulletin, 88, 588-606.

Bentler, P.M., \& Chou, C.P. (1987). Practical issues in structural modeling. Sociological Methods and Research, 16, 78-117.

Bernstein, J.H., \& Carmel, S. (1996). Medical and psychosocial predictors of morbidity and mortality: Results of a 26 year follow-up. Israel Journal of Medical Sciences, 32, 205-210.

Blane, D. (1995). Social determinants of health: So- cioeconomic status, social class, and health. American Journal of Public Health, 85, 903-905.

Bollen, K.A. (1989). Structural equations with latent variables. New York: John Wiley \& Sons.

Bradley, B.J. (1998). Establishing a research agenda for school nursing. Journal of School Health, 68, 53-61.

Byrne, B.M. (1994). Structural equation modeling with EQS and EQS/Windows. Thousand Oaks, CA: Sage. Campbell, J., Finch, D., Allport, C., Erickson, H., \& Swain, M.A.P. (1985). A theoretical approach to nursing assessment. Journal of Advanced Nursing, 10, 111-115.

Danziger, S., \& Gottschalk, P. (1995). America unequal. New York: Harvard University Press.

Darling-Fisher, C., \& Kline Leidy, N. (1988). Measuring Eriksonian development in the adult: The Modified Erikson's Psychosocial Stage Inventory. Psychological Reports, 62, 747-754.

Dunn, H.L. (1961). High-level wellness. Arlington, VA: R.W. Beatty.

Erickson, H.C. (1976). Identification of states of coping utilizing physiological and psychological data. Unpublished master's thesis, The University of Michigan, Ann Arbor.

Erickson, H.C. (1984). Self-care knowledge. Dissertations Abstracts International, 45, 1731. (University Microfilms No. AAD84-12136).

Erickson, H.C., \& Swain, M.A.P. (1982). A model for assessing potential adaptation to stress. Research in Nursing \& Health, 5, 93-101.

Erickson, H.C., Tomlin, E., \& Swain, M.A.P. (1988). Modeling and role-modeling: A theory and paradigm for nursing. Lexington, SC: Pine Press.

Erikson, E. (1982). The cycle of life. New York: W.W. Norton.

Fitzpatrick, J.J., \& Whall, A.L. (1989). Conceptual models of nursing: Analysis and application. Norwalk, CT: Appleton \& Lange.

Fry, E. (1968). A readability formula that saves time. Journal of Reading, 18, 513.

Garrison, R.J., Gold, R.S., Wilson, P.W.F., \& Kannel, W.B. (1993). Education attainment and coronary heart disease risk: The Framingham offspring study. Preventive Medicine, 22(1), 54-64.

Goble, F.G. (1974). The third force. The psychology of Abraham Maslow. New York: Pocket Books.

Grossman, M., \& Joyce, T.J. (1989). Socioeconomic status and health: A personal research perspective. In J.P. Bunker, D.S. Gomby, \& B.H. Kehrer (Eds.), Pathways to health (pp. 139-163). Menlo Park, CA: The Henry Kaiser Family Foundation.

Guralnik, J.M., Land, K.C., Blazer, D., Fillenbaum, G.G., \& Branch, L.G. (1993). Educational status and active life expectancy among older blacks and whites. The New England Journal of Medicine, 329, 110-116.

Hayduk, L.A. (1987). Structural equation modeling with LISREL. Baltimore, MD: Johns Hopkins University Press.

House, J.S., Kessler, R.C., Herzog, R., Mero, R.P., Kinney, A.M., \& Breslow, M.J. (1990). Age, socioeconomic status, and health. Milbank Quarterly, 68, $383-411$. 
Hu, L., \& Bentler, P.M. (1999). Cutoff criteria for fit indexes in covariance structure analysis: Conventional criteria versus new alternatives. Structural Equation Modeling: A Multidisciplinary Journal, 6(1), 1-55.

Igoe, J., \& Giordano, B.P. (1992). Expanding school health services to serve families in the 21 st century. Washington, DC: American Nurses Association.

Irvin, B.L., \& Acton, G.J. (1996). Stress mediation in caregivers of cognitively impaired adults: Theoretical model testing. Nursing Research, 45, 160-166.

Kessler, R.C., Foster, C.L., Saunders, W.B., \& Stang, P.E. (1995). Social consequences of psychiatric disorders, I: Educational attainment. American Journal of Psychiatry, 152, 1026-1032.

Kinney, C.K., \& Erickson, H.C. (1990). Modeling the client's world: A way to holistic care. Issues in Mental Health Nursing, 11, 93-108.

Kline, N. (1988). Psychophysiological processes of stress in people with a chronic physical illness (Doctoral dissertation, The University of Michigan). Dissertation Abstracts International, 49, 2129B.

Kline Leidy, N., Ozbolt, J., \& Swain, M.A.P. (1990). Psychophysiological processes of stress in chronic physical illness: A theoretical perspective. Journal of Advanced Nursing, 15, 478-486.

Lavin, A.T., Shapiro, G.R., \& Weill, K.S. (1992). Creating an agenda for school-based health promotion: $\mathrm{A}$ review of 25 selected reports. Journal of School Health, 62, 212-228.

Leidy, N.K. (1990). A structural model of stress, psychosocial resources, and symptomatic experience in chronic physical illness. Nursing Research, 39, 230236.

Leidy, N.K. (1994). Operationalizing Maslow's theory: Development and testing of Basic Need Satisfaction Inventory. Issues in Mental Health Nursing, 15, 277 295.

Leidy, N.K., \& Darling-Fisher, C.S. (1995). Reliability and validity of the Modified Erikson Psychosocial Stage Inventory in diverse samples. Western Journal of Nursing Research, 17, 168-187.

MacKenzie, E.J., Morris, J.A., Jurkovich, G.J., Yasui, Y., Cushing, B.M., Burgess, A.R., DeLateur, B.J., McAndrew, M.P., \& Swiontkowski, M.F. (1998). Return to work following injury: The role of economic, social, and job-related factors. American Journal of Public Health, 88, 1630-1637.

Marsh, H.W., Antill, J.K., \& Cunningham, J.D. (1989). Masculinity and femininity: A bipolar construct and independent constructs. Journal of Personality, 57, $625-663$.

Marsh, H.W., Hau, K.T., Balla, J.R., \& Grayson, D. (1998). Is more ever too much? The number of indicators per factor in confirmatory factor analysis. Multivariate Behavioral Research, 33, 181-220.

Maslow, A.H. (1968). Toward a psychology of being. Princeton, NJ: Van Nostrand.

Maslow, A.H. (1970). Motivation and personality (2nd ed.). New York: Harper \& Row.

Miller, E.H. (1989). The Positive Health Index: Development and psychometric assessment (Health Index).
Chicago: University of Illinois at Chicago, Health Sciences Center.

National Center for Health Statistics. (1993). Health United States, 1992 and Healthy people 2000 review. Hyattsville, MD: Public Health Service.

Nunnally, J. (1978). Psychometric theory. New York: McGraw-Hill.

Pappas, G., Queen, S., Hadden, W., \& Fisher, G. (1993). Increasing disparity in mortality between socioeconomic groups in the United States, 1960 and 1986. The New England Journal of Medicine, 329, 103109.

Pender, N.J., Barkauskas, V., Hayman, L., Rice, V.H., \& Anderson, E.T. (1992). Health promotion and disease prevention: Toward excellence in nursing practice and education. Nursing Outlook, 40, 106-112.

Pender, N.J., \& Pender, A.R. (1987). Health promotion in nursing practice. Norwalk, CT: Appleton \& Lange.

Porter, C.P., \& Villarruel, A.M. (1993). Nursing research with African American and Hispanic people: Guidelines for action. Nursing Outlook, 41(2), 5967.

Reed, P. (1991). Nursing theory of self-transcendence. ANS: Advances in Nursing Science, 13, 64-77.

Reutter, L., Neufeld, A., \& Harrison, M.J. (1998). Nursing research on the health of low-income women. Public Health Nursing, 15, 109-122.

Rogers, S. (1996). Facilitative affiliation: Nurse-client interactions that enhance healing. Issues in Mental Health Nursing, 17, 171-184.

Sappington, J., \& Kelly, J.H., (1996). Modeling and Role-Modeling theory: A case study of holistic care. Journal of Holistic Nursing, 14, 130-141.

Sobel, D.S. (1995). Rethinking medicine: Improving health outcomes with cost-effective psychosocial interventions. Psychosomatic Medicine, 57, 234244.

Stacy, A.W., Bentler, P.M., \& Flay, B.R. (1994). Attitudes and health behavior in diverse populations. Health Psychology, 13, 73-84.

Syme, S.L. (1987). Social determinants of disease. Annals of Clinical Research, 19, 44-52.

Uphold, C.R., \& Graham, M.V. (1993). Schools as centers for collaborative services for families: A vision for change. Nursing Outlook, 41, 204-211.

Walker, P.H., Baker, J.J., \& Chiverton, P. (1998). Costs of interdisciplinary practice in a school-based health center. Outcomes Management for Nursing Practice, 2(1), 37-44.

Walsh, F. (1996). The concept of family resilience: Crisis and challenge. Family Process, 35, 261-281.

Werner, J.S., \& Frost, M.H. (Eds.). (in press). Stress and coping: State of the science and implications for nursing theory, research, and practice. Glenview, IL: Midwest Nursing Research Society.

Williams, A.R., \& DeLurgio, S.A. (1994). Path analysis: Reflections on causal modeling. In K.A. McCormick, S.R. Moore, \& R.A. Siegel (Eds.), Clinical practice guidelines development: Methodology perspectives (pp. 77-83). Washington DC: AHCPR. AHCPR Pub. No. 95-0009. 
Williams, D.R. (1990). Socioeconomic differentials in health: A review and redirection. Social Psychology Quarterly, 53, 81-99.

Winkleby, M.A., Fortmann, S.P., \& Barrett, D.C. (1990). Social class disparities in risk factors for dis- ease: Eight-year prevalence patterns by level of education. Preventive Medicine, 19, 1-12.

World Health Organization. (1988). Basic documents (37th ed.). Geneva: Arbor. 